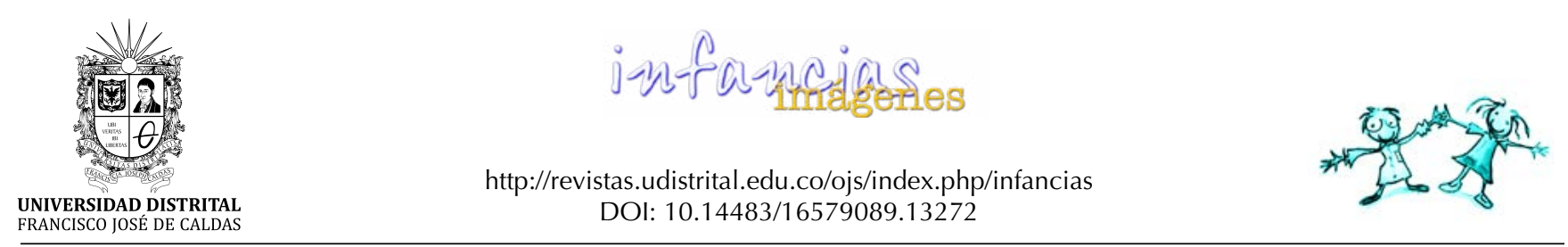

TEXTOS Y CONTEXTOS

\title{
La infancia soñada: el niño en la perversión pedófila
}

\author{
The Dreamed Childhood: The Child in Pedophile Perversion \\ Herwin Eduardo Cardona Quitián ${ }^{1}$
}

Para citar este artículo: Cardona, H. E. (2018). La infancia soñada: el niño en la perversión pedófila. Infancias Imágenes, 17(2), 209-218

\section{Resumen}

Los informes del Instituto Nacional de Medicina Legal señalan que la violencia sexual contra los niños va en aumento y los datos muestran que el agresor es casi siempre un familiar. La violencia sexual contra los niños evidencia un comportamiento perverso del adulto que genera interrogantes sobre las razones que motivan su acción. ¿Qué lugar ocupa el niño en la sociedad contemporánea? ¿Por qué los marcos de protección son insuficientes para atender esta problemática? El presente artículo se desprende de la tesis doctoral "Infancias deshabitadas", desarrollada en el Doctorado en Psicoanálisis de la Universidad de Antioquia. El método es indiciario y el enfoque psicoanalítico. Se presentan adelantos parciales sobre el comportamiento perverso pedófilo. Los hallazgos permiten comprender algunas causas de dicho comportamiento: por un lado, analiza el lugar que ocupa el niño en la economía psíquica de sus padres y, por otro, la relación que establece la sociedad contemporánea con la infancia.

Palabras clave: infancia, sexualidad, pedofilia, sociedad contemporánea, violencia sexual.
Recibido: 27-abril-2018 / Aprobado: 14-junio-2018

\begin{abstract}
Reports from the National Institute of Forensic Medicine indicate that sexual violence against children is increasing and the data shows that the aggressor is almost always a relative. Sexual violence against children demonstrates an adult perverse behavior that raises questions about the reasons that motivate their actions. What place does the child occupy in contemporary society? Why are the protection frameworks insufficient to attend this problem? This paper is derived from the doctoral thesis "Infancias deshabitadas" [Uninhabited infancies], developed in the Doctorate in Psychoanalysis of the University of Antioquia. The method is indicative and the approach is psychoanalytic. Partial advances on perverse pedophile behavior are presented. The findings allow the understanding of some causes of these behaviors: on the one hand, it analyses the place that the child occupies in the psychic economy of his/her parents and, on the other, the relation that establishes the contemporary society with the childhood.
\end{abstract}

Keywords: childhood, sexuality, pedophilia, contemporary society, sexual violence.

1 Psicopedagogo, Magíster en Psicoanálisis, Subjetividad y Cultura. Doctorante en Psicoanálisis, Universidad de Antioquia. Docente-investigador, Universidad Católica Luis Amigó, Universidad Pedagógica Nacional. Correo electrónico: jonasdorado@hotmail.com 


\section{Introducción}

"La infancia no existe, es el sueño del pedófilo". Philippe Forest

De acuerdo con el informe Forensis, del Instituto Nacional de Medicina Legal y Ciencias Forenses (2015), en los últimos 10 años la violencia sexual en Colombia presenta una leve tendencia al aumento. Las cifras más altas se dan en 2011, con una tasa de 48.08 por cada 100 mil habitantes, mientras que en el 2014 existe un aumento del $1.81 \%$. Los datos muestran que existe una mayor incidencia de los casos de abuso sexual en los niños y adolescentes (0-17 años) con un $85.08 \%$ de los registros. En la distribución por sexo el mayor número de casos en niñas se encuentra en el rango entre los 10 a los 14 años, mientras que en los niños es entre los 5 y 9 años. El principal lugar en el que se presentan los hechos es la vivienda, con un $76.01 \%$ de los casos. Predomina como agresor algún familiar con el $40.50 \%$ de los casos, seguido de un conocido $24.72 \%$. "La actividad que ejercía la víctima en el momento del hecho fue actividades vitales o relacionadas con el cuidado personal" (Instituto Nacional de Medicina Legal y Ciencias Forenses, 2015, p. 277). Las horas con mayor pico se encuentran entre las 3 de la tarde y las 9 de la noche, con un 35.7\% de los casos. Las ciudades con más altos índices de casos por presunta violencia sexual son Bogotá, Medellín y Cali. Según lo indica el informe:

[...] una de las realidades más palpables de nuestro país, en la que al igual se presenta mayor riesgo, probabilidad y exposición al desarrollo de la violencia sexual es el conflicto armado colombiano, y en varias regiones del país este tipo de violencia se ha convertido en un instrumento de guerra. (Instituto Nacional de Medicina Legal y Ciencias Forenses, 2015, p. 279)

Agregan, además, que la violencia sexual relacionada con el conflicto se ha practicado de múltiples formas, incluyendo "características como tortura, mutilación, asesinatos de niños no nacidos, la violación en presencia de miembros de la familia y la violación en grupo" (p. 280).
Llama la atención el lugar del que procede la violencia. Las cifras muestran que existe más probabilidad de ser abusado en casa que fuera de ella, que las horas de mayor riesgo están a plena luz del día y que las actividades de cuidado generan más propensión al abuso. En conclusión, la violencia sexual viene del más próximo, aquel quien tiene a su cargo el cuidado del niño. Dos elementos se entrelazan en el caso descrito: cuidado y violencia. Protección y violencia parecen intrincarse en el fenómeno de la violencia contra los niños, tanto en el caso del abuso sexual como en el caso del asesinato. Es como si el niño, puesto como objeto de goce, Ilamara a cruzar el umbral, el límite proscrito del "No matarás". Sin embargo, no ha existido otra época en la historia con más prescripciones para el cuidado y la protección de los niños.

Así, el presente trabajo tiene como objetivo comprender el acto pedófilo desde la perspectiva del psicoanálisis. Se parte de los siguientes interrogantes: ¿cómo es que el niño pasa a ser ese objeto sobre el que se desbordan las pulsiones de los adultos?, ¿cuál es el valor erótico del niño?, ¿por qué, en ocasiones, la relación con el niño traspasa las relaciones de ternura y culmina en una violencia de tipo sexual? El recorrido que acá se plantea se despliega en tres momentos: primero el niño como objeto en la economía pulsional; Segundo, el mecanismo de la perversión; y, por último, la relación entre pedofilia e infantolatría.

\section{Primero: el niño como objeto en la economía pulsional}

Los tiempos del movimiento pulsional que Freud describe permiten observar un lugar potencial para el acto pedófilo. Los dos casos que toma en su exposición son fundamentales para el esclarecimiento de la pulsión. Tanto el acto sádico como el voyerismo están presentes en la pedofilia.

\section{Sadismo y masoquismo}

"El sadismo consiste en una acción violenta, en una afirmación de poder dirigida a otra persona como objeto" (Freud, 1992, p. 123). El primer movimiento que podría definir la acción violenta sobre el niño: el acto sádico. Hay un segundo tiempo en el 
que el "objeto es resignado y sustituido por la persona propia" (Freud, 1992, p. 123). Momento intermedio definido por la vuelta contra sí mismo; el cual puede denominarse narcisista. El yo es tomado como objeto. El cuerpo propio es tomado como objeto a martirizar, a pesar de que el agente del martirio siga siendo uno mismo. Pero este tiempo es transitorio, pues finalmente se busca una persona ajena que tome el papel de sujeto y se encargue ahora de agenciar el martirio. Hablamos, ahora sí, de un masoquismo propiamente dicho.

Aventurémonos en la siguiente elucubración: la posición sádica, también definida por Freud como acción de dominio sobre los objetos, y que puede verse en la infancia, es un tiempo de la perversión polimorfa por la que todo niño atraviesa. Observaciones detalladas de Klein (2008) sobre la destrucción del objeto, posición paranoide y la vuelta de este movimiento contra sí mismo en la posición maniacodepresiva, dan cuenta de cómo el niño, para proteger el objeto de la destrucción que su pulsión sádica le impone, toma a su propio yo como objeto a martirizar. Tiempo intermedio en el que agente y objeto coinciden.

Pensemos ahora en el paso siguiente: introducir a un tercero para que realice la acción de martirizar; es decir, movimiento de sometimiento al otro. Ese último tiempo es quizá el mecanismo por el cual pueden mantenerse tanto al infantil perverso de la acción de martirizar, como al niño objeto del martirio en la vuelta contra sí mismo de la pulsión. Es de esta segunda posición, la de ser objeto del martirio, que aparece la otra escena para completar el circuito, reuniendo los dos primeros tiempos. El tercero evoca tanto la intención de martirizar como el goce de martirizarse. Así pues, cuando aparece el agente sádico para realizar esta escena perversa no puede más que cristalizar en ella dos posiciones experimentadas por él mismo, aunque siempre de manera insuficiente: martirizar-martirizarse. En esta escena el perverso intenta encarnar al gran $\mathrm{Otro}^{2}, \mathrm{O}$ al menos se presenta como su fiel servidor. Él es el objeto/medio para la realización de la escena

2 Es importante señalar la distinción realizada por Lacan entre el Otro con mayúscula o Gran Otro y el otro con minúscula. El primero hace referencia al Otro de la cultura, mientras el otro (con minúscula) señala al semejante. perversa. Encarna entonces en la escena tanto lo infantil perverso en la acción de martirizar, como el niño sometido a la acción de martirizarse a sí mismo.

Arriesgaré una hipótesis: por definición, la tarea del padre en la relación con el niño le expone a una situación en la que parece posible encarnar al tercero excluido de la escena. Aunque la función de dicho lugar es simbólica, no descarta la posibilidad de que intente ocuparse por una persona de la realidad. Este es un lugar dispuesto por el movimiento pulsional para que alguien se ubique allí como sujeto para martirizarme. Pero este lugar es siempre supuesto, no es convenido, a menos que se trate de un acuerdo sadomasoquista. Es decir, este lugar tercero es el lugar del gran Otro, que en cuanto lugar simbólico reinicia el circuito pulsional sin que la respuesta de goce sea efectiva. Es un lugar ajeno y libre, pero al mismo tiempo una instancia disponible para todo aquel que pueda venir a agenciar la acción, en este caso, de martirio. Es por efecto de un Ilamado de aquel atravesando por los tres tiempos de la pulsión, que aparece ese tercero que puede ocupar o no el lugar del agente de la acción sádica. Indiscutiblemente, el papel de los padres está a disposición para que la puesta en escena se complete. En conclusión, el circuito de la pulsión ofrece por estructura un lugar potencial que puede o no ser ocupado por el cuidador, instalando la posibilidad de seducción adulta cuyo desborde puede llevar al acto pedófilo o al acto violento.

\section{Ver y mostrarse}

La mirada está presente también en la relación pedófila. Si bien Freud menciona las mismas etapas del sadismo (ver, verse, ser mirado), introduce un tiempo anterior: ver parte del cuerpo propio. Este tiempo plantea un placer de ver asociado a una parte del cuerpo que, sin embargo, es puesta como fuera de él. Ver parte del cuerpo propio no es igual a verse. Por un lado, el objeto es parcial, por otro, esa parte del cuerpo no es experimentada de manera subjetiva. Este tiempo anterior podría considerarse como autoerótico. Freud dice: "en efecto, inicialmente la pulsión de ver es autoerótica" (1992, p. 125). Aunque indica que esta etapa previa faltaría en el sadismo, no la descarta del todo, ya que 
puede observarse en el intento del niño por apoderarse de sus propios medios.

Este tiempo inicial es descrito por Freud como narcisista. Del mismo modo, considera que en los dos casos, tanto el placer pasivo de ver como un posible masoquismo originario, mostrarían una permutación del sujeto narcisista por un sujeto ajeno por vía de la identificación. Si aceptamos esta afirmación, podemos volver sobre el esquema del sadismo para considerar el masoquismo como momento originario. ¿Qué tenemos, entonces, en el acto sádico? Un movimiento de identificación con el goce de aquel a quien se dirige la agresión. Ahora bien, ¿qué hay del lado del voyerismo-exhibicionismo originario? Un placer de ver parte del cuerpo propio, que en el acto voyerista es también identificación del mirón con el objeto de la exhibición. Es por esta vía que se alcanza también la falta de objeto, es decir, si aquello que antecede la mirada es la presencia de objeto; ante su ausencia habrá un intento de renegación que busca taponar la falta. Esto constituye la posición perversa por excelencia, el fetichismo sobre el que puede recaer tanto la pulsión sádica como la pulsión escópica. Lo primero es desarrollado por Freud en Tótem y tabú, a propósito del comportamiento de los hombres primitivos, quienes dirigían su agresión contra objetos fetiches; lo segundo se expone a partir del comportamiento del fetichista, quien detiene su mirada en el pie o en el zapato de la mujer para convertirlo en el objeto que viene al lugar de la falta para renegarla.

¿Pero cuál es la función del voyerismo en la pedofilia? No podemos olvidar que la pulsión es para Freud autoerótica y parcial, del mismo modo que la fuente de la pulsión escópica no es el ojo sino el órgano al que se dirige la mirada. Así, lo que confluye en el acto perverso pedófilo es una pulsión de apoderamiento del cuerpo del niño, el cual aparece como objeto de la mirada, el cual revive la marca del origen de la pulsión de ver: el órgano, o más precisamente, el cuerpo fetichizado del niño. La conclusión es que el cuerpo del niño en la economía pulsional se ofrece como objeto de la mirada en cuanto puede ser fetichizado. Es decir, cumple una doble condición: es moldeable y puede taponar la falta de la madre.

\section{La transformación en lo contrario}

Volvamos a los datos expuestos al inicio sobre los casos de abuso sexual infantil ${ }^{3}$. La estadística muestra que el abuso proviene casi siempre de un próximo, la mayoría de las veces un familiar. ¿Cómo es posible que el más próximo sea al tiempo el agresor? ¿Cómo es que ese objeto amado se convierte unas veces en objeto odiado, violentado y hasta violado?

Continuemos transitando por pulsiones y destinos de pulsión. Vimos, por un lado, cómo el circuito de la pulsión implica una vuelta contra sí mismo y cómo se puede transformar en su contrario, pasando de la actividad a la pasividad. Sin embargo, el caso más radical de la transformación en lo contrario es la del amor en odio. Advierte Freud la frecuencia en que aparecen los dos sentimientos simultáneamente dirigidos al mismo objeto y ve en esto el más claro ejemplo de la ambivalencia de sentimientos. Aquello que une estas dos polaridades es la sexualidad.

Según Freud, el amor es susceptible de tres oposiciones: amar-odiar, amor-indiferencia, amar y ser amado. El tiempo intermedio es pues el tiempo

3 Abuso sexual infantil se define como "A. la utilización, la persuasión, la inducción, la seducción o la coerción de un niño o niña para realizar [o participar de] —incluida la ayuda a otra persona para el mismo fin-cualquier tipo de conducta sexual explícita, o la simulación de dicha conducta con el fin de producir una representación visual de esta, o B. la violación, el tocamiento, la prostitución o cualquier otra forma de explotación sexual de un niño o niña, o el incesto" (Unicef, 2015, p. 25). En otras definiciones, se plantea que abuso sexual son "todos los actos de naturaleza sexual impuestos por un adulto sobre un niño, que por su condición de tal carece del desarrollo madurativo, emocional y cognitivo para dar consentimiento a la conducta o acción en la cual es involucrado. La habilidad para enredar a un niño en estas actividades se basa en la posición dominante y de poder del adulto en contraposición con la vulnerabilidad y la dependencia del niño" (Unicef, 2015, p. 25).

Es importante señalar la diferencia entre la concepción de abuso sexual, la perversión y el acto pedófilo. En la definición de abuso sexual entrarían todos los fenómenos de utilización de los niños en conductas sexuales, sean estos consentidos o no por ellos. Observemos que en la definición hay una concepción del niño como alguien que carece de desarrollo madurativo y emocional para dar consentimiento. Para el psicoanálisis, por el contrario, el niño no es solo pasivo frente a la sexualidad, pues existe una experiencia sexual temprana, que Freud define como perversa-polimorfa. En tal sentido el niño puede ejercer también un rol activo en la seducción. Ahora bien, la perversión para el psicoanálisis constituye un proceso estructural, es decir, la pulsión por estructura es perversa polimorfa. Asunto distinto es el acto pedófilo, en el que la perversión se materializa en la relación con el niño a partir de la seducción adulta, u otras perversiones llevadas al acto. 
narcisista de la pulsión, que puede observarse en el reflexivo: amarse a sí mismo. Freud agrega otras tres polaridades para lograr comprender la situación: sujeto-objeto, placer-displacer y activo-pasivo.

La primera oposición tiene que ver con las relaciones entre el organismo y el medio. Freud afirma que en parte el sujeto es capaz de satisfacer de manera autoerótica las pulsiones por sí mismo. En este momento el mundo exterior no está investido con interés, o más bien, es indiferente para la satisfacción. Este es considerado como un tiempo en el que el sujeto está en coincidencia con el placer, mientras el mundo exterior le es indiferente unas veces, displacentero otras. Así pues, cuando el sujeto encuentra el placer en él mismo, es indiferente frente al mundo. La primera posición de amar es entonces amar en sí mismo lo placentero-ser indiferente frente al mundo.

El papel de distinción adentro-afuera es realizado por el yo, lo que hace que aparezcan dos polaridades dentro del yo: yo-realidad y yo-placer. Es decir, incorporación de placer del mundo externo y proyección del yo de aquello que se experimenta como hostil. Así, a la polaridad amor-indiferencia, a través de la experiencia placer-displacer, se le agrega otra diferenciación: adentro-afuera. De manera que el yo coincide con el placer, mientras el mundo exterior coincide con el displacer.

A través del narcisismo entra en juego ahora una última polaridad: amar-odiar. Mientras el objeto placentero es aportado desde el mundo exterior por las pulsiones de autoconservación y es internalizado, todo lo hostil y displacentero es arrojado afuera. La función del odio es arrojar afuera lo displacentero. Ahora la indiferencia, que estaba afuera, queda supeditada al odio. Así pues, lo exterior, el objeto y lo odiado que eran coincidentes al principio, pasan a convertirse, por el mecanismo de introyección-incorporación, siempre que la experiencia sea placentera, en objetos amados. Pero puede ocurrir también todo lo contrario; y es que, por esa vía, los objetos se conviertan en odiados.

Ahora la polaridad amor-indiferencia se reduce a la polaridad yo-mundo exterior y la polaridad amor-odio a la polaridad placer-displacer. Lo que ocurre con el narcisismo es que dichas polaridades entran en la relación de objeto. Así, cuando el objeto es fuente de placer se incorpora, mientras que cuando el objeto es displacentero se aumenta la distancia entre el objeto y el yo, repitiendo así la huida del mundo exterior. El yo odiará entonces a todos los objetos que se constituyen en fuentes displacenteras.

Para Freud: "el amor proviene de la capacidad del yo para satisfacer de manera autoerótica, por la ganancia de un placer de órgano, una parte de sus mociones pulsionales" (1992, p. 133). Eso quiere decir que el amor es originariamente narcisista, y es de esa manera que se desplaza a los objetos que se incorporan. ¿Qué indica esto en el caso del niño? Por un lado, que el amor que se dirige al niño es siempre un amor narcisista. Por otro, que la manera en la que se expresa este amor es a través de la incorporación, pues la pulsión busca incorporar al objeto placentero. Freud afirma que:

Etapas previas del amar se presentan como metas sexuales provisionales en el curso del complicado desarrollo de las pulsiones sexuales. Discernimos la primera de ellas en el incorporar o devorar, una modalidad del amor compatible con la supresión de la existencia del objeto como algo separado, y que por tanto puede denominarse ambivalente. (1992, p. 133)

Así pues, el niño como objeto de la pulsión puede ser literalmente incorporado y devorado en el acto de incorporación. También lo contrario, puede ser dañado o aniquilado de manera indiferente. Ese podría ser el caso del asesinato ${ }^{4}$.

\section{Dos: la perversión}

El perverso es alguien que vive para el goce y que a su vez sabe sobre el goce propio y el ajeno. Él predica su evangelio "afirmando sus derechos sobre el cuerpo, ostentando su dominio" (Braunstein, 2005, p. 177). Se dice que el perverso es alguien que reniega la castración. Lo que quiere decir que conoce la castración del Otro, reconoce la falta y se ofrece a colmarla. El perverso es alguien cuyo fin es generar el deseo del otro. Desmiente la ignorancia

4 En Freud la pulsión sádica está relacionada con la organización anal, la cual está asociada tanto al apoderamiento del objeto como con su aniquilación. El odio aparece erotizado en el sadismo y aunque en principio está asociado a la autoconservación, la sexualidad se apuntala luego en dicha experiencia. 
de la relación sexual y le da valor de verdad a las teorías sexuales que, como sabemos, fracasan debido a una pieza que falta para lograr una explicación completa del acto sexual. Esta pieza faltante en el psiquismo infantil, pero también ausente en el logos, es la diferencia sexual de la mujer.

El perverso llena entonces con un dominio imaginario los huecos del saber. Lo único que le interesa es proveerse los medios para asegurar el goce. Así pues, lo que pretende es "alcanzar el goce a través del saber y del poder sobre un objeto inanimado, reducido a la abyección o amarrado por un contrato" (Braunstein, 2005, p. 179). Es aquí donde el cuerpo del niño, o de la víctima, puede estar al servicio de su perversión. Lo que se busca es escenificar su fantasma y hacer verosímil el goce que la castración obliga a renunciar.

El perverso es alguien que desmiente la realidad (lo sé, pero... aun asî). Se instala en la castración para, desde allí, montar el teatro de su fantasma. Tapona la falta de la madre con el fetiche. Por esta vía, el perverso promueve la ley del abuso del otro, el goce como supremo bien y la violación del otro para acceder al goce. Así pues, esta es una forma de goce que no pasa por el deseo. Se trata de una extensión de los límites, pero sobre todo derecho al goce. Vive para el goce, para su administración y organización. El perverso se aferra entonces a un goce primario infantil. Lo fundamental es que el Otro no puede estar castrado. El perverso intenta sostener la universalidad del falo y, por esta vía, se convierte en instrumento de goce del Otro. "Como si fuera ese Otro y como si tuviera a su cargo asegurar la no castración" (Braunstein, 2005, p. 185).

El perverso se convierte en un objeto, en un instrumento al servicio del Otro.

Él es el fetiche que venera, él es el látigo con que flagela a su víctima, él es el contrato con que esclaviza a su flagelador [...] él es un falo que positiviza al falo, que niega que el falo falte" [...]. Él es la causa por la que el Otro se divide. (Braunstein, 2005, p. 185)

¿Cuál es entonces el papel que juega aquí el niño como objeto de goce? Braunstein (2005) afirma que el perverso necesita de un sujeto que experimente la división.
El niño violado o seducido, el aterrado espectador de la exhibición, la histérica humillada [...] hasta llegar al borde del desvanecimiento por la escenificación intolerable que rompe las fronteras de la conciencia, del pudor y del asco. Ese otro que no ha de ser complaciente sino violentado, resistente, suplicante. (Braunstein, 2005, p. 186)

Pero, en este tránsito, es el perverso el que se convierte en objeto, mientras el otro se revela como aquel que, a través del sufrimiento, alcanza el goce:

El fantasma encubridor del yo que trata como objeto al otro de su acción revela, más allá de su imaginario, que sucede exactamente lo contrario: es el perverso quien es el objeto y es su víctima quien es el sujeto, más aún, quien, por la manipulación perversa, transciende las barreras del placer y se encuentra con el goce que está más allá. La paradoja es que el perverso [...] acaba por volcar el goce sobre dos vertientes contrapuestas, la del Otro cuya falta es desmentida y la del otro cuyo goce es alcanzado por el camino del sufrimiento y del dolor. (Braunstein, 2005, p. 186)

\section{Tres: pedofilia e infantolatría}

Que el mecanismo de la pulsión ofrezca un lugar potencial para el acto pedófilo ${ }^{5}$ no quiere decir que el fenómeno pueda generalizarse. Aunque las cifras de abuso sexual van en aumento, no se trata de un fenómeno nuevo. Lo nuevo sería más bien la positivización de la proscripción en la ley, por un lado, y el escándalo que suscita en la sociedad contemporánea, por otro. ¿Qué es entonces lo generalizable? Según Laplanche (1987), lo generalizable es la seducción que opera el adulto a través del cuidado y la ternura, vía por la cual se introduce la sexualidad en el niño. No obstante, que exista una seducción generalizada tampoco resuelve el asunto del que nos ocupamos, pues no todos los padres abusan de sus hijos. Puede decirse, sin embargo, que existe una intención de seducción, y que el papel del niño no es solamente pasivo en esta relación. Por un lado, el niño está investido por el afecto narcisista

5 El acto pedófilo es aquel que culmina en la relación sexual efectiva, mientras que en la perversión pedófila hay, por decirlo así, destinos sublimados de la pedofilia. Esto podemos verlo en la pedagogía, o en el mito de Pigmalión. 
de sus padres; por otro, el desenvolvimiento pulsional del niño busca la respuesta del otro.

Lo cierto es que la pedofilia no siempre estuvo proscrita. De hecho, como lo indica Serge André (1999), en las sociedades helénicas constituía un ritual de iniciación de los jóvenes en la vida sexual. Los atenienses la consideraban la relación ideal en el acto pedagógico. Los romanos mantenían relaciones con niños a condición de que no fueran ciudadanos romanos. Esta práctica también se extendió a los monasterios de la edad media en los que eran comunes las relaciones pedófilas entre monjes y jóvenes novicios. Según lo indica el informe de abuso sexual de la Unicef (2015), algunos forenses franceses documentaron varios casos de pedofilia a mediados del siglo XIX, y fue solamente hasta la década del 70 y el 80 del siglo XX que se introdujo el problema en las agendas de la política pública. De manera que la cacería del pedófilo constituye un fenómeno contemporáneo, mientras las leyes de protección a la infancia cobran cada vez más fuerza, llegando incluso hasta la idolatría del niño intocable.

Infantolatría y pedofilia nos aparecen ahora como dos caras de la misma moneda, en la que el doble vínculo protección/violencia da cuenta de la relación contemporánea con la infancia. La infantolatría es un neologismo que introduce Serge André. Su pregunta al respecto es si esta:

¿No corre el riesgo de llevarnos hacia una forma de pedofilia generalizada y triunfante? Esta hipótesis podría en todo caso explicar las manifestaciones de horror y de pánico que el pedófilo despierta hoy día en nuestra sociedad. ¿Este horror no sería finalmente el horror ante la revelación de la significación de nuestra propia idealización de la infancia? (André, 1999, p. 16)

En todo caso, el extremo de sobreprotección ha desembocado en una cacería de brujas y la sospecha constante ante cualquier tipo de vínculo adulto-niño. Tampoco puede dejarse de lado que el abuso sexual ha tomado múltiples matices: desde pornografía infantil, prostitución, venta de niños, hasta la promoción del consumo a través de la erotización de los cuerpos infantiles. De hecho, buena parte de la seducción del capitalismo se realiza por esta vía.

Lo cierto es que el cuerpo infantil se presenta como un objeto que invita a transgredir los límites del goce; el mecanismo parte de la economía pulsional, pero se articula a dispositivos de disciplinamiento y de mercado. En el caso de los padres, el cuidado y la crianza ubican al niño como objeto narcisista a ser moldeado. Algo similar ocurre en la escuela que tiene a su cargo la socialización y la formación. Aquí, el niño se presenta como la figura de Pigmalión (Mijolla, 2008) que puede ser moldeada a imagen y semejanza de su escultor. Pero si de un lado los padres y los profesores forman al niño e instalan dinámicas de cuidado, de otro, aparece el deseo de castigarlos cruelmente.

\section{Moldear al niño a imagen y semejanza}

La pedofilia se define como amor a los niños. Normalmente el pedófilo no recurre a la violación, pues busca el consentimiento del niño. Incluso lo que pretende es demostrar que el niño está sumergido en una sexualidad que le es prohibida por el mundo adulto. El violador, por el contrario, requiere de la resistencia del otro, para mostrar que goza por la fuerza. Según André (1999), el amor del pedófilo es un amor sensual que actúa en rivalidad con el amor materno, por considerar que esta roba la parte erótica del amor que el padre siente por el niño. El pedófilo busca, además, un niño cuyo cuerpo aún no ha elegido su sexo. Una especie de ser asexuado que contrasta muy bien tanto con la infantolatría que promueve el mercado, como con la sacralización del niño en la sociedad contemporánea. Según André (1999), lo que le atrae al pedófilo es que ese cuerpo aparentemente asexuado rechaza la castración y la diferencia de los sexos. Lo que busca hacer aparecer en la figura del niño es él mismo, su propia imagen. Es por eso que Pigmalión se ofrece como figura paradigmática: "Él mismo se ha quedado convertido en un eterno niño imaginario, atado a ser lo que podría llenar la falta del deseo de su madre" (André, 1999, p. 15). Paraíso del que ha sido expulsado y al que tiene que volver. Lo que pone en escena el pedófilo es el intento de completitud de la madre a través de su escena con el niño asexuado. 
Mijolla (2008) ha explorado el caso de la pedofilia a partir del fantasma de Pijmalión, quien moldea a la exacta medida de su deseo una joven mujer. El objeto enigmático de su deseo es lo que hace fascinante su escultura, la cual deviene un fetiche vivo. Según indica Mijolla, ese cuerpo encierra el enigma del paso de la inmovilidad del cadáver a la vida. El cuerpo fetiche busca entonces ser animado en la escenografía del pedófilo, actuando un papel previamente esbozado en el libreto. El problema aparece cuando el actor se sale de su libreto. El fetiche está en todo caso en una franja gris entre la vida y la muerte. Entre lo extraño y lo familiar. Esta fascinación es encarnada por el cuerpo del niño y es también lo que es explotado, además, por el mercado y la publicidad. El peligro estriba en lo que menciona Mijolla: "Nada de sorprendente que pueda fascinar al perverso, a riesgo de llevarlo a la muerte de su fetiche para intentar perforar el misterio" (2008, p. 9). Aquí aparece otra vez la oscilación entre la pulsión sádica y el voyerismo. El niño como objeto que fascina realiza un Ilamado a ese que podría ubicarse en el lugar potencial y llevarlo incluso hasta la muerte. Incorporación y destrucción se hacen presentes como destinos pulsionales.

Según el mito de Pigmalión, reconstruido desde varias versiones por Mijolla (2008), lo que buscaba el escultor era defenderse de la maldición proferida por Venus, quien intentando frenar los abusos cometidos en su nombre por Afrodita, transformó a los hombres en tarados y a las mujeres en estatuas. Así pues, la maldición hacia los hombres fue que su deseo bestial no respondiera más que a la indiferencia cosificada de la puta. Pigmalión, a quien define Mijolla (2008) como un niño de María, busca resistirse al paso por las sacerdotisas prostitutas y por eso crea la estatuilla de la cual se enamora. Su estatuilla de marfil representa una virgen blanca e inmóvil. El creador se enamora de su fetiche y ella deviene un cuerpo vivo y moldeable. Objeto que el escultor aprisiona en sus dedos, acaricia y amasa. Así, el hombre creador de la estatuilla se convierte ahora en propiedad de ella. Como dice Mijolla (2008), el creador ha esculpido su estatuilla para devenir el niño de María. Así pues, lo que muestra Pigmalión es que la madre sobre la que se organiza la economía de la pedofilia no es la madre fálica, como se podría considerar, sino la madre santa. Sutil distinción que Lacan enfatizó a propósito de la perversión.

\section{El niño de María}

En el caso de la perversión subsisten los siguientes elementos: primero, la desmentida de la castración de la madre. Allí se albergan dos enunciados contradictorios: 1) la madre está castrada; 2) no, la madre no está castrada. Segundo, el padre es reducido a ser un actor de comedia, pues quien detenta el falo es la madre. Tercero, el fantasma para el perverso es algo que pone en escena y se hace público. La puesta en escena del fantasma implica la seducción o la corrupción del partenaire, en la cual busca la complicidad forzada del otro. Cuarto, el perverso aboga por una ley superior y natural del goce sin límites; lejos de transgredir, lo que busca es obedecer la ley.

Retomemos la fórmula de Lacan: "A mujer Santa, hijo perverso" (2009, p. 531). Según Izcovich (2016) "la mujer Santa es aquella que no se orienta de modo tal que es el hombre el portador del falo" (p. 37). ¿Cómo entender esto en la sociedad contemporánea? ¿En una época que promueve el goce sin límites y promulga la liberación sexual de la mujer? Quizá en esto el capitalismo también sea el llamado a responder.

La cita de Lacan al respecto aclara la cuestión:

[...] todo el problema de las perversiones consiste, en concebir cómo el niño en su relación con la madre, relación constituida en el análisis, no por su dependencia vital, sino por la dependencia del amor, es decir, por el deseo de su deseo, se identifica al objeto imaginario de ese deseo, en tanto que la madre, ella misma, lo simboliza en el falo. (2009, p. 531)

Recordemos que el padre es aquel que fija el límite ante el goce materno. Goce que, según Izcovich, se impone desde dos lugares: el primero viene del gran Otro y determina la falta; el segundo viene de la pareja sexual hacia la cual se dirige el deseo de la madre. Es decir, lo que hace límite a que el niño ocupe el lugar de deseo de la madre es que su deseo se dirija hacia otro. Según Izcovich (2016): "falta la falta en la madre del perverso" (p. 41), lo que quiere decir que se trata de una madre que se 
vive como completa. Así pues, "la mujer santa sería aquella que hizo de su hijo, o hija, el falo que la completa como mujer, de modo tal, que ella puede hacer como si el deseo por un hombre es algo de lo cual ella puede excluirse" (p. 42). La madre fálica encuentra entonces su sutura en el hijo. El hijo se convierte en el complemento de goce. Se trata de una madre abnegada que se extrae de todo goce más allá del hijo.

Este es el valor que tiene el fetiche para el perverso, pues es aquello que le permite sostener la imagen de la madre completa. Esa es la manera como el perverso enfrenta la falta del Otro. En eso radica la función que tiene para el pedófilo la imagen moldeable de la estatuilla, en su intento por construir no solo la madre santa, sino al niño de María. El perverso es entonces aquel que dedica sus esfuerzos a hacer existir La mujer ${ }^{6}$. Contrario a la mujer santa, la mujer fálica es para Lacan aqueIla que deja caer al niño, su bien más preciado. La mujer santa, en cambio, no concibe al falo más que del lado del niño. "La mujer santa es aquella que aparentemente es sin ningún goce, pero que espera como contrapartida que su hijo le aporte el único goce válido en la existencia" (Izcovich, 2016 p. 50). Lo que intenta el perverso es completar el goce divino a partir de la posición de objeto. Pero en este escenario la crueldad no puede estar exenta del acto perverso, pues lo que busca es hacer emerger la mirada de Dios. Según Izcovich, para el perverso el punto de fascinación absoluto es el encuentro con lo que pueda suscitar el más horrible horror. "Lo que se busca es la angustia del otro para hacer surgir la mirada de dios" (2016, p. 61).

\section{A manera de conclusión: ¿por qué nos causa tanto horror?}

La preocupación por la pedofilia es un asunto reciente en la historia; así como también el enfoque de derechos en el tratamiento de la infancia. El resultado de este proceso ha sido la sacralización del niño y la

6 Es importante señalar que La mujer tiene una connotación especial para el psicoanálisis lacaniano. A partir de las formulaciones de Freud sobre las teorías sexuales infantiles, en las que observa que en la experiencia infantil no es posible configurar la diferencia sexual de la mujer, Lacan propone su fórmula: La mujer no existe. Con esto pretende señalar el autor que la mujer es no-toda simbolizable. sobrevaloración de la infancia. André contrasta la situación con las ovaciones recibidas por Tony Duvert, un literato que escribió en la década del 70 sobre relaciones homosexuales y pedófilas, y el rechazo generalizado que a partir de la década del 80 comenzó a hacerse frente a los casos de pedofilia.

¿Qué pasó entonces entre 1980 y 1995 para que la opinión pública sufriera un cambio tan espectacular? [...] El fenómeno es especialmente significativo puesto que nuestras sociedades occidentales contemporáneas parecen desde entonces cimentadas en el ideal sacrosanto, pero puramente imaginario, del niño-rey y por la obsesión correlativa de la protección de la infancia. (p. 6)

De un lado, sacralización del niño; de otro, violencia atroz. He aquí de nuevo el fenómeno para el cual aún no encontramos respuesta definitiva.

Quizá la respuesta no se encuentre únicamente en el registro intrapsíquico, y acaso sea necesario indagar por las coordenadas culturales que han dado lugar a dichos cambios. Según André (1999), estamos al borde de un delirio colectivo que puede registrarse en el comercial televisivo de la década del 90: "En Nestlé el niño es el Rey" (p. 6). El niño encarna la mercancía más preciada en la contemporaneidad, y quizá, por la misma razón, se instala una demanda a gozar de él, a hacer de su cuerpo un fetiche. Dos figuras se entrelazan aquí: el niño como gran empresario y el gran empresario como un niño innovador. Estamos ante un momento histórico en el que las diferencias generacionales parecen borrarse. Por esta vía, parece lógico que una de las modalidades de goce sea la pedofilia, con la salvedad de que se trata de una relación entre un niño-adulto y un adulto-niño. El ideal que se impone entonces en la cultura contemporánea es el de permanecer siendo niños. El resultado no puede ser otro que la infancia generalizada.

\section{Referencias}

André, S. (1999). La significación de la pedofilia. Conferencia en Lausanne. Traducción de Guillermo Rubio. Recuperado de: https://es.scribd.com/document/139668128/ La-Significacion-de-La-Pedofilia-Serge-Andre 
Braunstein, N. (2005). La perversión y la desmentida del goce. En Goce. México D.F.: Siglo XXI Editores. Freud, S. (1992). Pulsiones y destinos de pulsión. En Obras Completas (vol. XIV, pp. 113-134). Buenos Aires: Amorrortu.

Fondo de las Naciones Unidas para la infancia (Unicef) (2015). Abuso sexual infantil. Montevideo: Unicef.

Instituto Nacional de Medicina Legal y Ciencias Forenses (2015). Informe 2014 Forensis Datos para la vida. Bogotá: Imprenta Nacional.

Izcovich, L. (2016). La perversión en psicoanálisis. Medellín, Colombia: Universidad Pontificia Bolivariana.
Klein, M. (2008). Contribución a la génesis de los estadios maniaco-depresivos. En Obras Completas (pp. 267-295). México: Paidós.

Lacan, J. (2009). De una cuestión preliminar a todo tratamiento posible de la psicosis. En, Escritos 2 (pp. 509-557). México: Siglo XXI.

Laplanche, J. (1987). Nuevos fundamentos en psicoanálisis. Buenos Aires: Amorrortu.

Mijolla, S. (2008). Le fantasme de Pygmalion. Topique, 3(104), 7-26. 